\title{
Special Column for Petroleum Geology \& Geophysics: State Key Laboratory of Petroleum Resources and Prospecting, China University of Petroleum
}

The State Key Laboratory of Petroleum Resources and Prospecting in China University of Petroleum (Beijing) was designated to be a state key laboratory by the Ministry of Science and Technology in 2007. It was founded on the basis of the Key Laboratory of Hydrocarbon Accumulation Mechanisms of the Ministry of Education and CNPC Key Laboratory of Geophysics. Professor Hao Fang serves as the director of the laboratory. His main research interest is in hydrocarbon accumulation mechanisms.

The laboratory aims to conduct inter-disciplinary co-operative research to tackle scientific challenges of national and international significance in the area of oil and gas resources. This will be achieved by developing and advancing theories of the formation and occurrence of complicated petroleum accumulations, by solving fundamental scientific problems involved in oil and gas exploration and by training highly-skilled professionals.

The laboratory has been awarded four National "973" Fundamental Research Projects, one National Oil and Gas Fundamental Research Project, three Key Research Projects funded by the National Science Foundation and five Key Research Projects funded by CNPC, Sinopec and CNOOC for the recent years. As a result, significant progress has been made in many areas including:

1) basin evolution and hydrocarbon generation, migration and accumulation;

2) hydrocarbon accumulation processes and hydrocarbon distribution in Mesozoic-Cenozoic continental rift basins in China;

3) hydrocarbon accumulation and destruction in marine superimposed basins in China;

4) hydrocarbon prospectivity and exploration risk analyses of foreign basins;

5) exploration technologies for complex geological conditions.

The laboratory has a number of outstanding young and middle-aged scientists who are eminent in the area of petroleum resources and exploration. They include one academician of the Chinese Academy of Sciences, one academician of the Chinese Academy of Engineering, three chief scientists of "973" research projects, four winners of Research Grants for Outstanding Young Chinese Scientists, two winners of Sun Yueqi Energy Awards, six winners of Science and Technology Awards for Outstanding Young Chinese Scientists, five scientists listed in the "One Hundred-One Thousand-Ten Thousand Outstanding Scientists Program" and twelve experts enjoying special government allowances. Currently, the laboratory has two Creative and Innovative Research Teams designated by the Ministry of Education. Under the guidance of academicians, several research teams of different disciplines have been set up and they are headed by a Changjiang Scholar or other outstanding young or middle-aged scholars. Our teams have the ability to carry out inter-disciplinary co-operative research. The laboratory has two post-doctoral research programs, six $\mathrm{PhD}$ programs and seven master's programs.

The laboratory has attracted a number of outstanding Chinese and overseas researchers. As visiting scholars, they have conducted co-operative research with our staff members. The laboratory has long-term co-operative research programs with twelve foreign universities and research organizations in USA, UK, Canada, Korea and Australia. The State Key Laboratory of Petroleum Resources and Prospecting has become an important base for academic exchanges. It has successfully hosted four international symposiums on hydrocarbon accumulation mechanisms and petroleum resources evaluation.

Under the leadership and support of the Ministry of Science and Technology and the Ministry of Education, the laboratory will strengthen its management, be further open to the outside world, and enhance international and domestic academic exchange. It will play a more important role in studies of hydrocarbon accumulation mechanisms, research and development of petroleum exploration technologies and training of highly-skilled professionals. 